\title{
Effect of Intraduodenal and Intravenous Triglyceride Infusions on Plasma Gastric Inhibitory Polypeptide and Insulin in Fetal and Neonatal Pigs
}

\author{
C. Kühl ${ }^{1,2}$, P.J. Hornnes ${ }^{2}$, S. Lindkaer Jensen ${ }^{3}$ and K. B. Lauritsen ${ }^{4}$ \\ ${ }^{1}$ Hvidøre Hospital, Klampenborg, ${ }^{2}$ Diabetes Centre, Departments of Obstetrics and Gynaecology YB and \\ ${ }^{3}$ Surgical Gastroenterology C, Rigshospitalet, and ${ }^{4}$ Department of Surgical Gastroenterology, Hvidovre Hospital, Copenhagen, Denmark
}

Summary. The responses of gastric inhibitory polypeptide (GIP) and insulin to intraduodenal and IV triglyceride infusions were measured in 11 late fetal and 10 neonatal pigs. Basal plasma glucose, insulin, and GIP concentrations were lower in fetal than in neonatal pigs. In the fetal pigs, plasma glucose increased slightly during intraduodenal and IV triglyceride infusions, whereas plasma insulin remained unchanged during the tests. No significant changes were observed in plasma GIP concentration following intraduodenal triglyceride infusion in the fetal pigs, but plasma GIP fell during the IV infusion of triglyceride in these pigs $(p<0.01)$. In the neonatal pigs, plasma glucose and insulin remained unaffected by in- traduodenal and triglyceride infusions. Plasma GIP did not change during the IV triglyceride infusion, but exhibited a paradoxical decline after the intraduodenal triglyceride infusion $(p<0.05)$. It is concluded that the GIP-cell response to an oral triglyceride load is suppressed in late fetal and neonatal pigs. The abolished GIP response to oral triglycerides could play a causal role in the inactivity of the enteroinsular axis which is seen in both human and animal neonates.

Key words: Gastric inhibitory polypeptide (GIP), control of GIP, plasma insulin, insulin secretion, plasma glucose, enteroinsular axis, fetal pigs, neonatal pigs.
It is well established that the effect of gastrointestinal hormones on insulin secretion, originally designated incretin [1] and later the enteroinsular axis [2], is mainly attributable to the insulin-releasing effect of gastric inhibitory polypeptide (GIP) [3]. In the human newborn the enteroinsular axis is inactive [4]. Neonatal pigs also lack an enteroinsular response and in this animal, the lack of an enteroinsular response might be related to a paradoxical decline in plasma GIP following oral glucose administration [5]. In contrast, adult pigs exhibit a significant enteroinsular axis effect [6]. GIP is present in the fetal gut [7], and intraduodenal infusion of glucose elicits a substantial rise in plasma GIP in late fetal pigs [5]. The porcine enteroinsular axis is thus already developed in late fetal life, but neonatally the axis seems to be blocked by a mechanism as yet unknown. As this reduces the enhancement of plasma insulin levels after a meal, the blocked enteroinsular axis might protect the neonate from insulin-induced hypoglycaemic attacks late in the intervals between suckling periods.

In the present study the effect of triglycerides, another potent GIP-releasing factor $[8,9]$, on plasma GIP and insulin concentrations in fetal and neonatal pigs has been investigated. To accomplish this, triglycerides were infused intraduodenally and IV into groups of fetal and neonatal pigs.

\section{Material and Methods}

\section{Animals}

Eleven fetal pigs ( 110 days of gestational age - duration of pregnancy in pigs is 124 days) from one Danish Landrace sow, and 10 neonatal pigs ( $72 \mathrm{~h}$ of age) from a similar sow were studied. The pregnant sow was fasted for $12 \mathrm{~h}$ before laparotomy, and all neonatal pigs were allowed to suckle at will until 3-4 h before investigation.

The experimental procedure has been described in detail previously [5]. In short, one or two fetuses in turn were exteriorized from the uterus of the anaesthetized sow and placed under infra-red lamps at the hypochondric area of her abdomen. The placenta and the umbilical cord were left in situ in order to allow normal fetal-maternal exchanges during the experiments. Five fetuses (weight $1209 \pm 119 \mathrm{~g}$ ) had an infant feeding tube placed with the tip in the duodenum, the position being checked by X-ray. In six other fetuses (weight $1124 \pm$ $147 \mathrm{~g}$ ) an indwelling catheter was placed in the internal jugular vein. All fetuses had catheters introduced into the carotid artery for blood sampling.

Indwelling catheters were also placed, under local anaesthesia, in the carotid arteries of all neonatal pigs and also in the internal jugular vein of six of these pigs (weight $2630 \pm 171 \mathrm{~g}$ ). The remaining four neonatal pigs (weight $2253 \pm 172 \mathrm{~g}$ ) had intraduodenally placed infant feeding tubes.

\section{Experimental Protocol}

In the fetal and neonatal pigs, Intralipid 10\% (a commercial preparation of soybean oil emulsion that contains mainly triglycerides) (Vitrum, Stockholm, Sweden) was infused by means of pumps, either 
Table 1. Fasting plasma levels of glucose, insulin, and GIP in 11 fetal and 10 neonatal pigs

\begin{tabular}{lccl}
\hline & Fetal & Neonatal & $p$ \\
\hline Glucose $(\mathrm{mmol} / \mathrm{l})$ & $3.2 \pm 0.2$ & $4.3 \pm 0.4$ & $<0.05$ \\
Insulin $(\mathrm{pmol} / \mathrm{l})$ & $37 \pm 3$ & $92 \pm 14$ & $<0.001$ \\
GIP $(\mathrm{pmol} / \mathrm{l})$ & $178 \pm 6$ & $323 \pm 35$ & $<0.001$ \\
\hline
\end{tabular}

Results expressed as mean \pm SEM

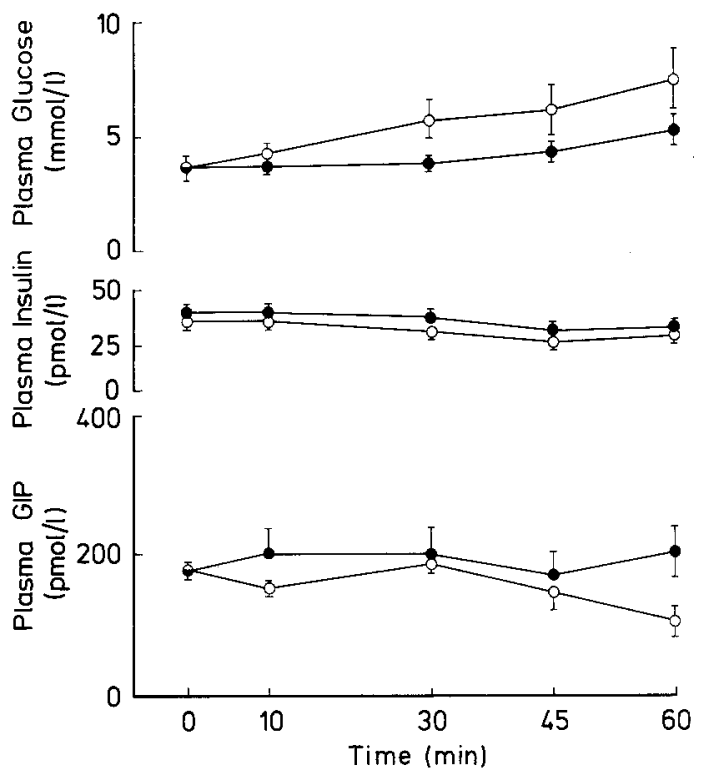

Fig. 1. Plasma glucose, insulin, and GIP concentrations (mean \pm SEM) in arterial blood from fetal pigs subjected to intraduodenal $(\bullet, n=5)$ or IV $(O, n=6)$ infusion of triglycerides

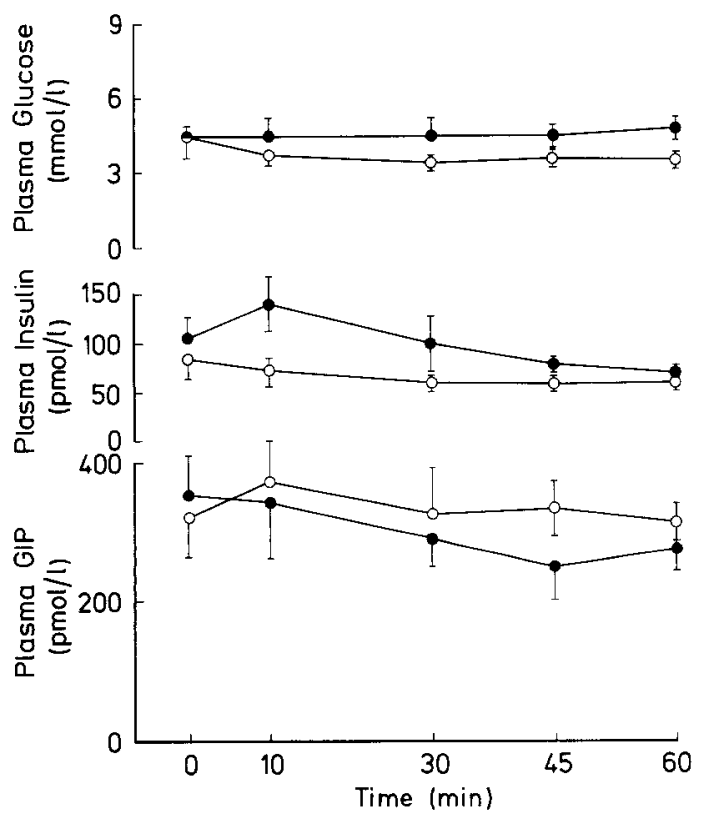

Fig. 2. Plasma glucose, insulin, and GIP concentrations (mean \pm SEM) in arterial blood from neonatal pigs subjected to intraduodenal $(\bullet, n=4)$ or IV $(O, n=6)$ infusion of triglycerides via the intraduodenal catheter $(4 \mathrm{ml}$ over $5 \mathrm{~min}$ in fetal pigs; $6 \mathrm{ml}$ over $5 \mathrm{~min}$ in neonatal pigs) or the IV catheter $(1.8 \mathrm{ml}$ over $60 \mathrm{~min}$ in fetal pigs; $3.0 \mathrm{ml}$ over $60 \mathrm{~min}$ in neonatal pigs).

\section{Laboratory Analyses}

Blood samples ( $3 \mathrm{ml}$ each) were drawn from the carotid artery catheter at $-10,-5,10,30,45$, and $60 \mathrm{~min}$, time zero being the start of triglyceride infusions. Blood was collected in chilled heparinized tubes containing $500 \mathrm{KIU}$ Trasylol $/ \mathrm{ml}$; portions were also taken for haematocrit determinations. The sampled volume of blood was replaced by saline $(154 \mathrm{mmol} / 1)$. The samples were separated at $4{ }^{\circ} \mathrm{C}$ within $30 \mathrm{~min}$, and the plasma stored at $-20^{\circ} \mathrm{C}$ until assayed for glucose by a dehydrogenase method [10] and for insulin [11] and GIP [12] by previously described radioimmunoassays. In the insulin radioimmunoassay a porcine insulin tracer, crystalline pork insulin standards, and a guinea pig antiporcine insulin serum were used. The GIP radioimmunoassay used porcine GIP tracer and standards. The anti-GIP serum used ( $R$ 65) does not cross-react with porcine vasoactive intestinal polypeptide, secretin, pancreatic glucagon, or gut glucagon-like immunoreactivity and recognizes both fat and glucose-stimulated GIP release $[12,13]$. It measures only the 5000 molecular weight form of the peptide. The sensitivity, intra-assay coefficient of variation and interassay coefficient of variation for the GIP assay were $4 \mathrm{pmol} / \mathrm{l}, 9.6 \%$ and $20 \%$, respectively. The corresponding values for the insulin assay were $4 \mathrm{pmol} / 1(0.6 \mathrm{mU} / 1), 3.3 \%$ and $10.5 \%$. In order to avoid interassay errors for insulin and GIP, all samples from one group of animals (fetal and neonatal pigs) were measured in single assays.

\section{Expression of Results}

All results are expressed as mean \pm SEM. Student's t-test was used for statistical evaluation, and differences resulting in $p$-values below 0.05 were considered significant.

\section{Results}

In all pigs, the mean decrease in the haematocrit value was small $(0.04 \pm 0.01$; range $0.00-0.10)$.

\section{Fasting Concentrations}

Table 1 shows the mean fasting concentrations of glucose, insulin, and GIP in the fetal and neonatal pigs. Glucose, insulin, and GIP were all significantly lower in the fetal pigs than in the neonatal pigs. In comparison, mean fasting glucose, insulin, and GIP concentrations in the pregnant sow were $3.6 \mathrm{mmol} / 1,42 \mathrm{pmol} / 1$, and $76 \mathrm{pmol} / \mathrm{l}$ respectively.

\section{Effect of Intraduodenal and Intravenous Infusions of Triglycerides on Plasma Insulin and GIP Concentrations in Fetal Pigs (Fig. 1)}

The mean plasma glucose concentrations of the two tests were not significantly different at any time point investigated, but both after intraduodenal and IV triglyceride infusions, plasma glucose exhibited a slight but significant increase $(p<0.05)$. Plasma insulin remained unchanged during both tests. Plasma GIP remained unchanged after intraduodenal triglyceride infusion but fell significantly after IV triglyceride infusion 
$(p<0.01)$. The $60 \mathrm{~min}$ GIP-value of the IV test was lower than the corresponding value of the intraduodenal test $(p<0.05)$.

\section{Effect of Intraduodenal and Intravenous Infusions of Triglycerides on Plasma Insulin and GIP Concentrations in Neonatal Pigs (Fig.2)}

Plasma glucose and insulin both remained unaffected by intraduodenal and IV triglyceride infusions. However, in the IV triglyceride infusion-experiments, plasma glucose levels were lower at 30-60 $\min (p<0.001)$ and insulin levels were lower at 10 and $45 \mathrm{~min}(p<$ 0.05 ) compared with the corresponding values observed after intraduodenal triglyceride administration.

Plasma GIP remained unaffected by IV triglyceride infusions but exhibited a paradoxical decline after intraduodenal triglyceride infusion (45 versus $0 \mathrm{~min}$, $p<0.05$ ).

\section{Discussion}

Basal plasma insulin and GIP concentrations were significantly higher in neonatal than in fetal pigs. This is in accordance with previous findings [5]. Basal GIP in the neonatal pigs was also considerably higher than the level in the pregnant sow or the levels normally found in adult man [14]. It is possible that basal GIP is enhanced neonatally because of the repeated feedings with breast milk which the neonate has received. Thus, in the human newborn infant, basal GIP was higher at day 6 than at birth and furthermore, at day 6, basal GIP was higher in a group of fed infants than in a group of sick preterm infants who had never been fed orally [15]. However, since even the basal plasma GIP concentration in fetal pigs is higher than that of the pregnant sow and the normal adult man, the enhanced basal plasma GIP in neonatal pigs cannot be attributed solely to repeated postnatal feeding. Preliminary results from our laboratory show that the concentration of GIP in amniotic fluid from normal pregnant women in the last trimester of pregnancy is more than twice the corresponding maternal plasma concentration $(133 \pm 19$ versus $51 \pm 8 \mathrm{pmol} / 1, p<0.05$ ). This seems to indicate that GIP secretion is also enhanced in the human fetus although the reason for this phenomenon remains to be elucidated.

Regardless of the route of administration, triglycerides were a poor stimulant of GIP secretion in fetal and neonatal pigs. In contrast to the reported finding of enhanced plasma GIP levels after orally administered triglycerides in healthy adults $[8,9,12]$, GIP exhibited a paradoxical decline after intraduodenal triglycerides in the neonatal pigs. It has previously been shown that in newborn infants, GIP is not stimulated by ingestion of milk [15, 16] or dextrose [17], whereas a significant GIP response to a milk feed was found at day 24 [15].
We have also recently shown that oral glucose is a poor stimulus for GIP secretion in neonatal pigs, whereas fetal pigs exhibited a substantial GIP surge after an intraduodenal infusion of glucose [5]. This finding together with those of the present study and others quoted previously [15-17] indicate that the inactive enteroinsular axis in the newborn human [4] and pig [5] is due to a profound disturbance of GIP release following food ingestion during this period of life. Since GIP does respond to at least oral glucose in late fetal life [5] whereas it does not increase after stimulation with glucose or triglycerides neonatally, it is conceivable that during the first days of life, the normal GIP response to nutrients is blocked by a factor as yet unknown. It is probable that this 'factor' is conveyed to the newborn by the first feed of breast milk. Studies in neonatal pigs prior to the first suckling period might therefore elucidate this problem.

The finding that plasma GIP remained unaffected by intraduodenal triglycerides in fetal pigs contrasts with the previous finding of a significant increase in plasma GIP following intraduodenal glucose infusion in fetal pigs of similar gestational age [5]. The discrepancy might reflect differences in the time of maturation of GIP secretion following stimulation with glucose or triglycerides.

Plasma insulin and glucose remained unaffected by IV and intraduodenal triglycerides in the neonatal pigs. The lack of response of GIP to intraduodenal triglycerides is therefore not explained by high plasma insulin or glucose [18-20] levels. Under euglycaemic experimental conditions, plasma insulin is also unaffected by oral or IV triglyceride loads in healthy adults [21,22].

Plasma glucose increased slightly but significantly during the triglyceride infusion in the fetal pigs. The reason for this finding is unknown but it could be due to glucagon release induced by lipid [23]. The role of lipids in the regulation of acute changes in plasma glucagon concentrations is, however, disputed [24] and, moreover, plasma glucose remained unaffected by triglycerides in the neonatal pigs. Measurement of plasma glucagon in fetal and neonatal pigs under similar experimental conditions is therefore necessary to solve this problem.

\begin{abstract}
Acknowledgements. The skillful technical assistance of V.Christiansen, J.Skovbjerg, C. Kühl, and L. Poulsen is gratefully acknowledged. The study was supported by grants from The Danish Hospital Foundation for Medical Research. Region of Copenhagen, The Faroe Islands and Greenland (J.no. 78-30 and 79-42), the Novo Foundation, and the P.Carl Petersen Foundation.
\end{abstract}

\section{References}

1. Zunz E, La Barre J (1929) Contributions à l'etude des variations physiologiques de la sécrétion interne du pancréas: relations entre les sécrétions externe et interne du pancréas. Arch Int Physiol Biochim 31: 20-44

2. Unger RH, Eisentraut AM (1969) Entero-insular axis. Arch Int Med 123: 261-266 
3. Brown JC, Otte SC (1978) Gastrointestinal hormones and the control of insulin secretion. Diabetes 27: 782-789

4. King KC, Schwartz R, Yamaguchi K, Adam PAJ (1977) Lack of gastrointestinal enhancement of the insulin response to glucose in newborn infants. Pediatrics 91: 783-786

5. Kühl C, Hornnes PJ, Lindkaer Jensen S, Lauritsen KB (1980) Gastric inhibitory polypeptide and insulin: Response to intraduodenal and intravenous glucose infusions in fetal and neonatal pigs. Endocrinology 107: 1446-1450

6. Lindkaer Jensen S, Nielsen OV, Kühl C (1976) The enteral insulinstimulation after pancreas transplantation in the pig. Diabetologia $12: 617-620$

7. Gespach C, Bataille D, Jarrousse C, Rosselin G (1979) Ontogeny and distribution of immunoreactive gastric inhibitory polypeptide (IR-GIP) in rat small intestine. Acta Endocrinol (Kbh) 90: 307-316

8. Falko JM, Crockett SE, Cataland S, Mazzaferri EL (1975) Gastric inhibitory polypeptide (GIP) stimulated by fat ingestion in man. $\mathrm{J}$ Clin Endocrinol Metab 41: 260-265

9. Pederson RA, Schubert HE, Brown JC (1975) Gastric inhibitory polypeptide. Its physiologic release and insulinotropic action in the dog. Diabetes 24: 1050-1056

10. Dolhofer R, Weiss L, Wieland OH (1976) Experience with the glucose-dehydrogenase-UV-method for the determination of blood glucose. J Clin Chem Clin Biochem 14: 415-417

11. Kühl C (1975) Glucose metabolism during and after pregnancy in normal and gestational diabetic women. I. Influence of normal pregnancy on serum glucose and insulin concentration during basal fasting conditions and after a challenge with glucose. Acta Endocrinol (Kbh) 79: 709-719

12. Lauritsen KB, Moody AJ (1978) The response of gastric inhibitory polypeptide (GIP) and insulin to glucose in duodenal ulcer patients. Diabetologia 14: 149-153

13. Christiansen J, Bech A, Fahrenknug J, Holst J, Lauritsen K, Moody AJ, Schaffalitzky de Muckadell O (1979) Fat-induced jejunal inhibition of gastric acid secretion and release of pancreatic glucagon, enteroglucagon, gastric inhibitory polypeptide, and vasoactive intestinal polypeptide in man. Scand $\mathbf{J}$ Gastroenterol 14: 161-166

14. Hornnes PJ, Kühl C, Holst JJ, Lauritsen KB, Rehfeld JF, Schwartz TW (1980) Simultaneous recording of the gastro-enteropancreatic hormonal peptide response to food in man. Metabolism 29: 777-779
15. Lucas A, Sarson DL, Bloom SR, Aynsley-Green A (1980) Developmental aspects of gastric inhibitory polypeptide (GIP) and its possible role in the enteroinsular axis in neonates. Acta Paediatr Scand 69: 321-325

16. Aynsley-Green A, Bloom SR, Williamson DH, Turner RC (1977) Endocrine and metabolic response in the human newborn to first feed of breast milk. Arch Dis Child 52: 291-295

17. Aynsley-Green A, Lucas A, Bloom SR (1979) The effect of feeds of differing composition on entero-insular hormone secretion in the first hours of life in human neonates. Acta Paediatr Scand 68: 265-270

18. Verdonk CA, Rizza RA, Nelson RL, Go VLW, Gerich JE, Service FT (1980) Interaction of fat-stimulated gastric inhibitory polypeptide on pancreatic alpha and beta cell function. J Clin Invest 65: 1119-1125

19. Andersen DK, Elahi D, Brown JC, Tobin JD, Andres R (1978) Oral glucose augmentation of insulin secretion. J Clin Invest 62: 152-161

20. Elahi D, Andersen DK, Brown JC, Haile TD, Herschcopf RJ, Raizes GS, Tobin JD, Andres R (1979) Pancreatic $\alpha$ - and $\beta$-cell responses to GIP infusion in normal man. Am $\mathbf{J}$ Physiol 237: E185-E191

21. Pelkonen R, Miettinen TA, Taskinen M-R, Nikkilä EA (1968) Effect of acute elevation of plasma glycerol, triglyceride and FFA levels on glucose utilization and plasma insulin. Diabetes 17 : $76-82$

22. Balasse EO, Ooms HA (1973) Role of plasma free fatty acids in the control of insulin secretion in man. Diabetologia 9: 145-151

23. Andrews SS, Lopez AS, Blackard WG (1975) Effect of lipids on glucagon secretion in man. Metabolism 24:35-44

24. Hicks BH, Taylor CI, Vij SK, Pek S, Knopf RF, Floyd JC, Fajans SS (1977) Effect of changes in plasma levels of free fatty acids on plasma glucagon, insulin, and growth hormone in man. Metabolism 26: 1011-102

Received: 24 April 1981

and in revised form: 9 March 1982

Dr. Claus Kühl

Hvidøre Hospital

Emiliekildevej 1

DK-2930 Klampenborg, Denmark 